Supplement of Geosci. Model Dev. Discuss., 7, 7861-7886, 2014

http://www.geosci-model-dev-discuss.net/7/7861/2014/

doi:10.5194/gmdd-7-7861-2014-supplement

(C) Author(s) 2014. CC Attribution 3.0 License.

(c) (i)

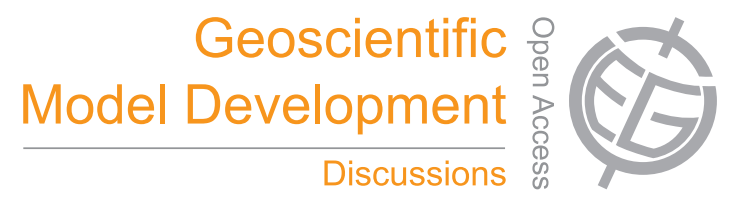

Supplement of

\title{
An observation-constrained multi-physics RCM ensemble for simulating European mega-heatwaves
}

\section{A. I. Stegehuis et al.}

Correspondence to: A. I. Stegehuis (annemiek.stegehuis@1sce.ipsl.fr) 


\section{Supplementary material}

2 Table S1: Final ranks.

\begin{tabular}{|c|c|c|c|c|c|c|}
\hline \multirow[t]{2}{*}{ Final rank } & \multicolumn{6}{|c|}{ Physic combinations } \\
\hline & $\mathrm{MP}$ & PBL & SF & RA & $\mathrm{CU}$ & SU \\
\hline 1 & 10 & 1 & 1 & 4 & 6 & 2 \\
\hline 2 & 6 & 5 & 5 & 4 & 3 & 2 \\
\hline 3 & 6 & 7 & 1 & 5 & 6 & 2 \\
\hline 4 & 8 & 5 & 5 & 4 & 14 & 2 \\
\hline 5 & 8 & 7 & 1 & 4 & 6 & 2 \\
\hline 6 & 8 & 7 & 1 & 5 & 6 & 2 \\
\hline 7 & 10 & 5 & 2 & 4 & 6 & 2 \\
\hline 8 & 6 & 1 & 1 & 3 & 6 & 2 \\
\hline 9 & 10 & 2 & 2 & 4 & 6 & 2 \\
\hline 10 & 10 & 5 & 5 & 4 & 6 & 2 \\
\hline 11 & 8 & 4 & 4 & 4 & 6 & 2 \\
\hline 12 & 8 & 5 & 5 & 4 & 3 & 2 \\
\hline 13 & 6 & 7 & 1 & 4 & 6 & 2 \\
\hline 14 & 8 & 5 & 2 & 4 & 14 & 2 \\
\hline 15 & 6 & 7 & 1 & 3 & 6 & 2 \\
\hline 16 & 6 & 4 & 4 & 4 & 6 & 2 \\
\hline 17 & 6 & 7 & 1 & 4 & 3 & 2 \\
\hline 18 & 6 & 5 & 5 & 4 & 14 & 2 \\
\hline 19 & 8 & 5 & 5 & 5 & 6 & 2 \\
\hline 20 & 8 & 1 & 1 & 5 & 6 & 2 \\
\hline 21 & 8 & 2 & 2 & 4 & 14 & 2 \\
\hline 22 & 6 & 2 & 2 & 5 & 6 & 2 \\
\hline 23 & 8 & 5 & 2 & 5 & 6 & 2 \\
\hline 24 & 6 & 5 & 2 & 4 & 14 & 2 \\
\hline 25 & 8 & 2 & 2 & 5 & 6 & 2 \\
\hline 26 & 8 & 5 & 2 & 3 & 6 & 2 \\
\hline 27 & 6 & 5 & 5 & 5 & 6 & 2 \\
\hline 28 & 8 & 1 & 1 & 5 & 3 & 2 \\
\hline 29 & 8 & 5 & 5 & 3 & 6 & 2 \\
\hline 30 & 6 & 5 & 2 & 3 & 6 & 2 \\
\hline 31 & 8 & 7 & 1 & 4 & 14 & 2 \\
\hline 32 & 8 & 1 & 1 & 4 & 14 & 2 \\
\hline 33 & 6 & 2 & 2 & 3 & 6 & 2 \\
\hline 34 & 6 & 7 & 1 & 4 & 14 & 2 \\
\hline 35 & 6 & 5 & 5 & 3 & 6 & 2 \\
\hline 36 & 6 & 2 & 2 & 4 & 14 & 2 \\
\hline 37 & 8 & 2 & 2 & 3 & 6 & 2 \\
\hline 38 & 10 & 5 & 5 & 4 & 1 & 2 \\
\hline 39 & 6 & 1 & 1 & 5 & 14 & 2 \\
\hline 40 & 10 & 5 & 2 & 4 & 1 & 2 \\
\hline 41 & 6 & 1 & 1 & 4 & 14 & 2 \\
\hline 42 & 10 & 1 & 1 & 4 & 1 & 2 \\
\hline 43 & 6 & 7 & 1 & 4 & 1 & 2 \\
\hline 44 & 6 & 5 & 5 & 5 & 1 & 2 \\
\hline 45 & 8 & 7 & 1 & 4 & 1 & 2 \\
\hline 46 & 8 & 2 & 2 & 4 & 1 & 2 \\
\hline 47 & 6 & 5 & 5 & 4 & 1 & 2 \\
\hline 48 & 8 & 5 & 2 & 4 & 1 & 2 \\
\hline 49 & 8 & 5 & 5 & 4 & 1 & 2 \\
\hline 50 & 8 & 6 & 6 & 4 & 1 & 2 \\
\hline 51 & 8 & 5 & 2 & 4 & 1 & 2 \\
\hline 52 & 6 & 5 & 2 & 5 & 1 & 2 \\
\hline 53 & 6 & 1 & 1 & 4 & 1 & 2 \\
\hline 54 & 8 & 1 & 1 & 4 & 1 & 2 \\
\hline 55 & 8 & 2 & 2 & 5 & 1 & 2 \\
\hline
\end{tabular}

3 
4 Figure S1: Simulated temperature min-max range during the heatwave of 2003 (1-15 August). The 5 range is calculated as the difference between the warmest and the coldest simulation during this period 6 between the 216 members of the ensemble.

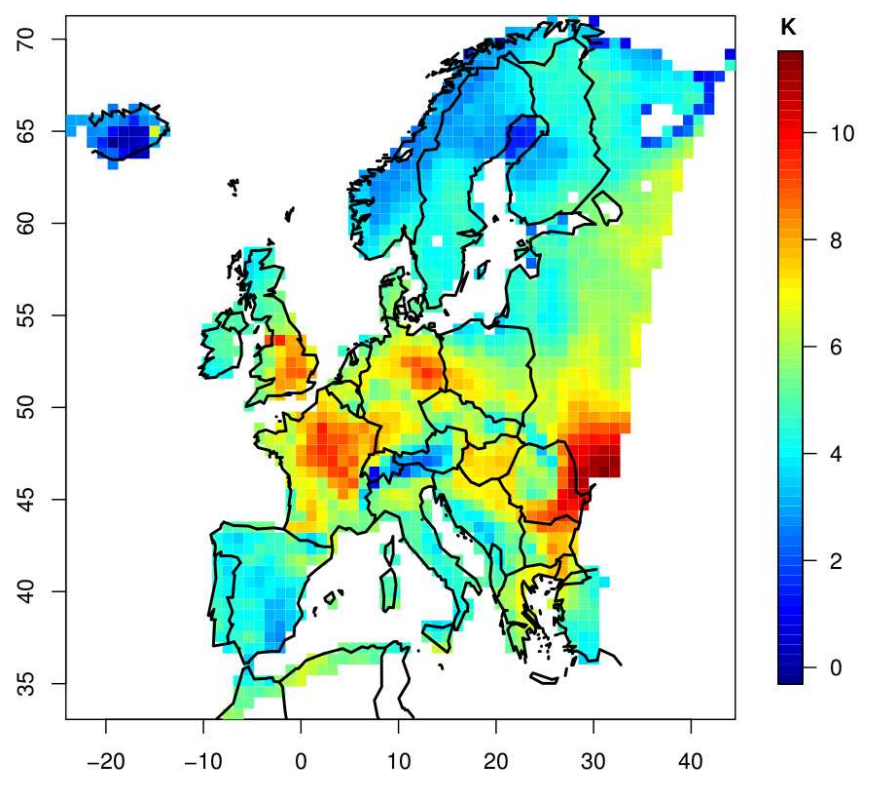


8 Figure S2a-d: Timeseries over France 2003 (a,b) and 2007 (c,d) and Russia (e,f) with maximum (a,c,e)

9 and minimum (b,d,f) daily temperatures. Every simulation is shown in gray and observations of E-OBS

10 in black. The blue and red lines are the coldest and the warmest simulations over France during the

11 heatwave. These lines have the same set of physics in all the figures.
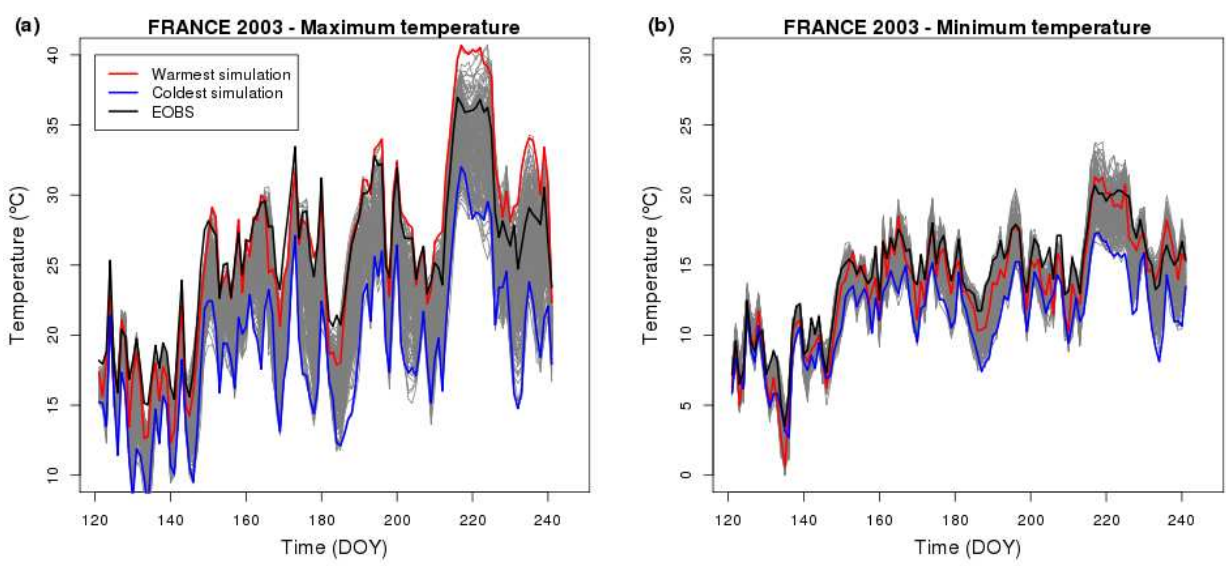

12
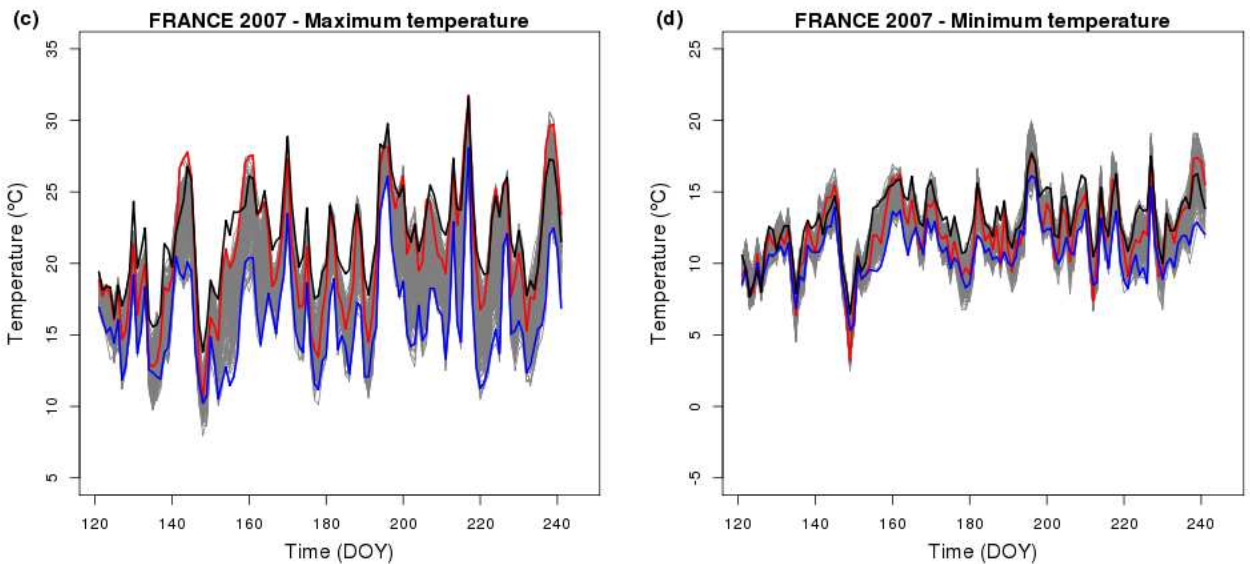

13
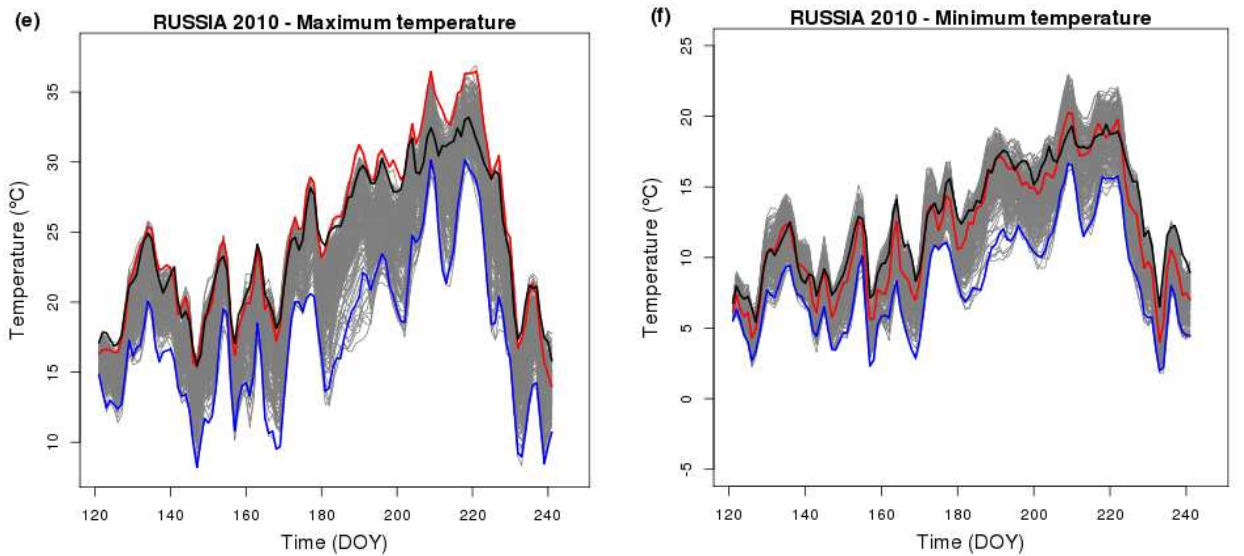
15 Figure S3a-d: Correlation between soil moisture content at July $31^{\text {st }}$ and precipitation in the preceding 16 months of June-July. Every point is one simulation. Different colors represent different physics for 17 convection (CU) (a), microphysics (MP) (b), radiation (RA) (c) and planet boundary layer-surface 18 (PBL-SF) (d).
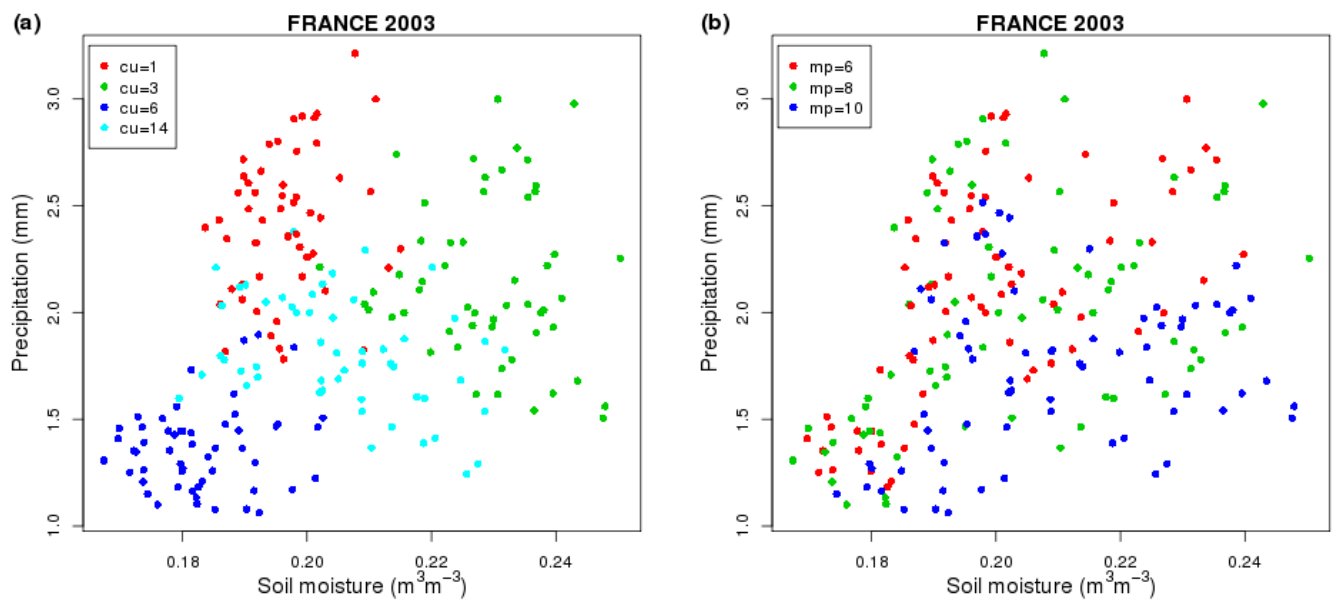

19
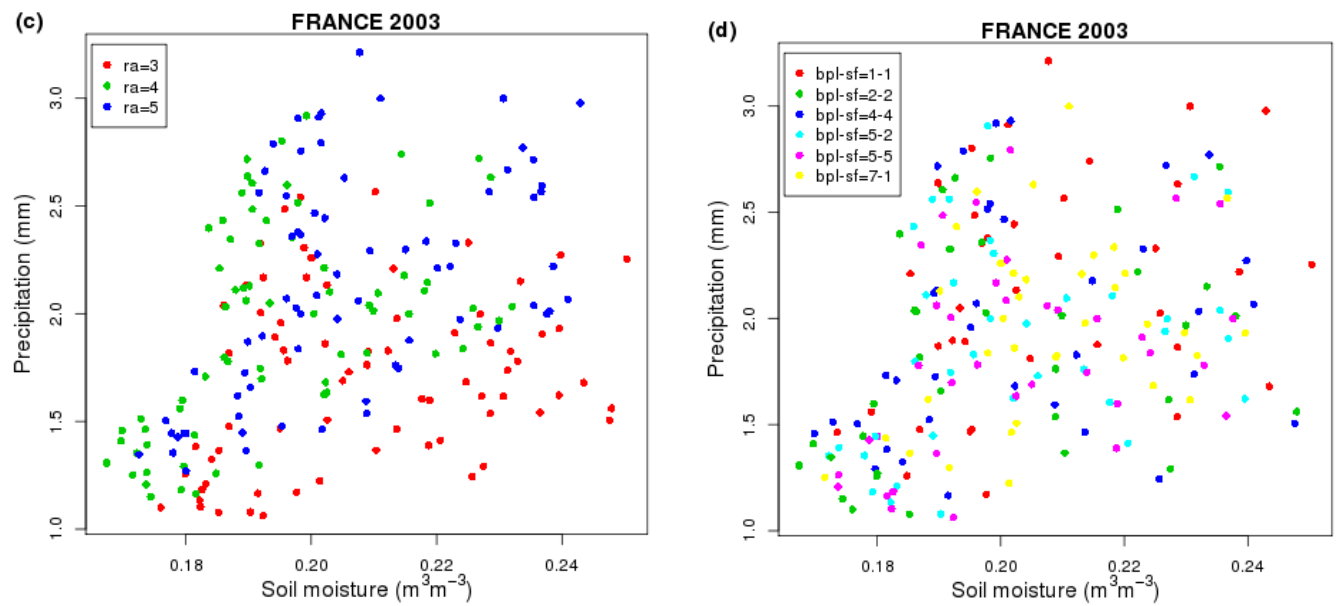
22 Figure S4a-d: Correlation between soil moisture content at the end of July and shortwave radiation

23 during the preceding months of June-July. Every point is one simulation. Different colors represent

24 different physics for convection (a), microphysics (b), radiation (c) and planet boundary layer-surface

25 (d).
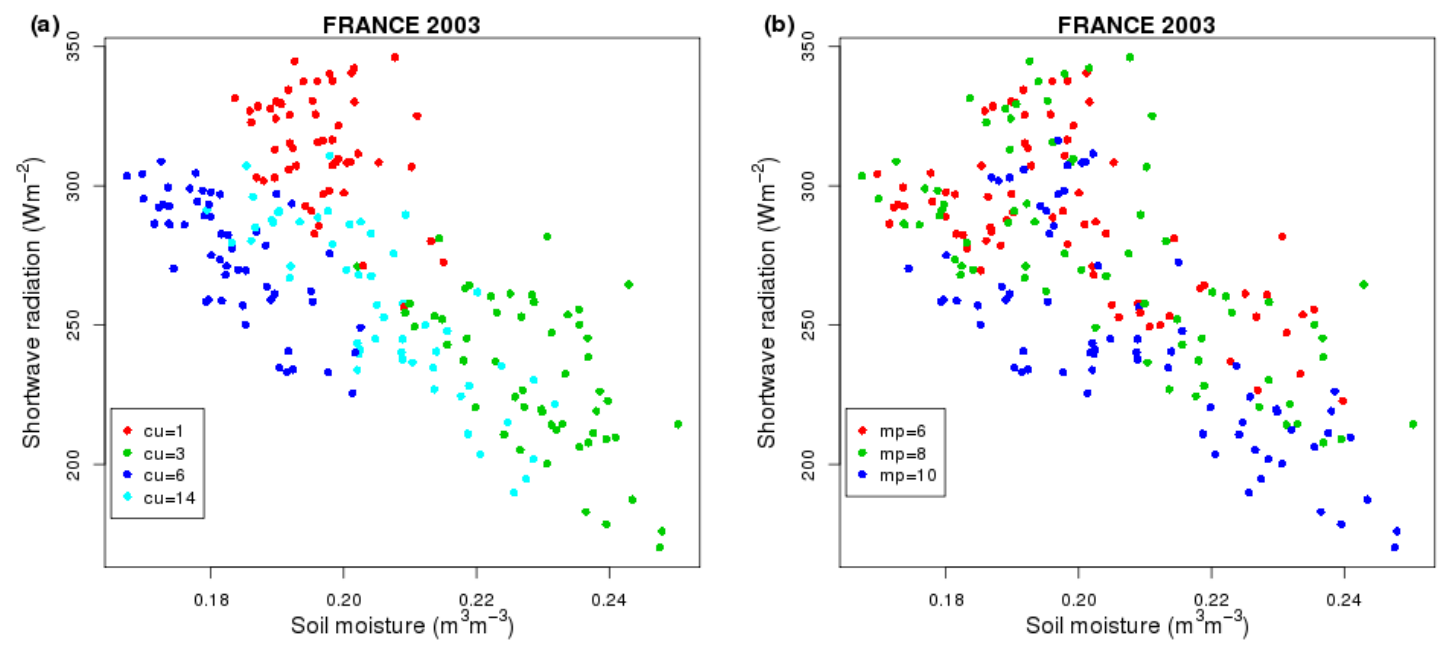

26
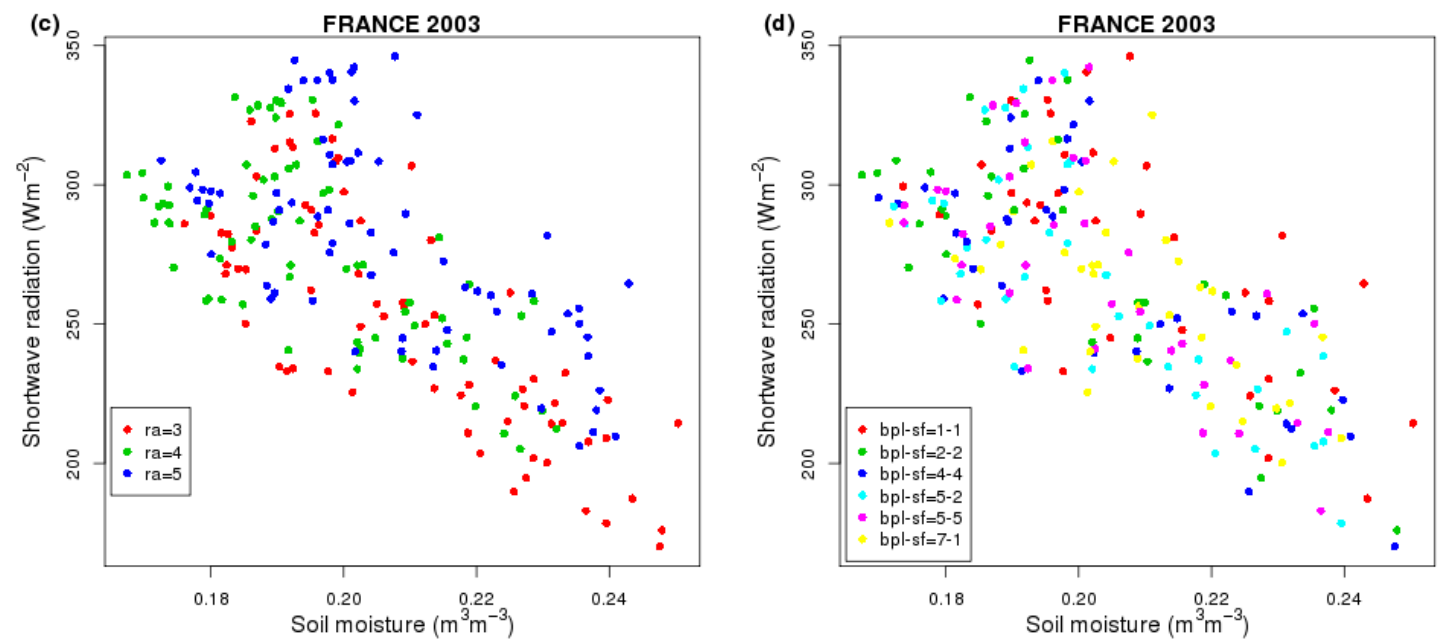
28 Figure S5a-f: Timeseries of temperature $(a, b)$, precipitation $(c, d)$ and latent heatflux $(e, f)$ over the 29 Iberian Penisula 2003 (a,c), Russia 2010 (b,d,e) and Scandinavia 2003 (f).
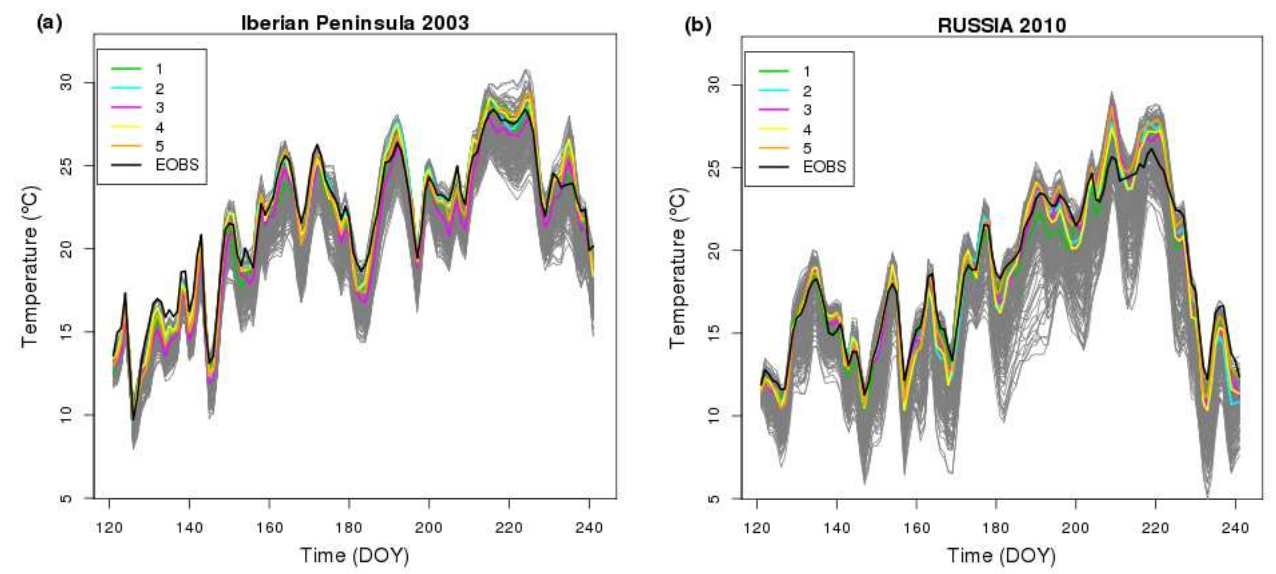

30
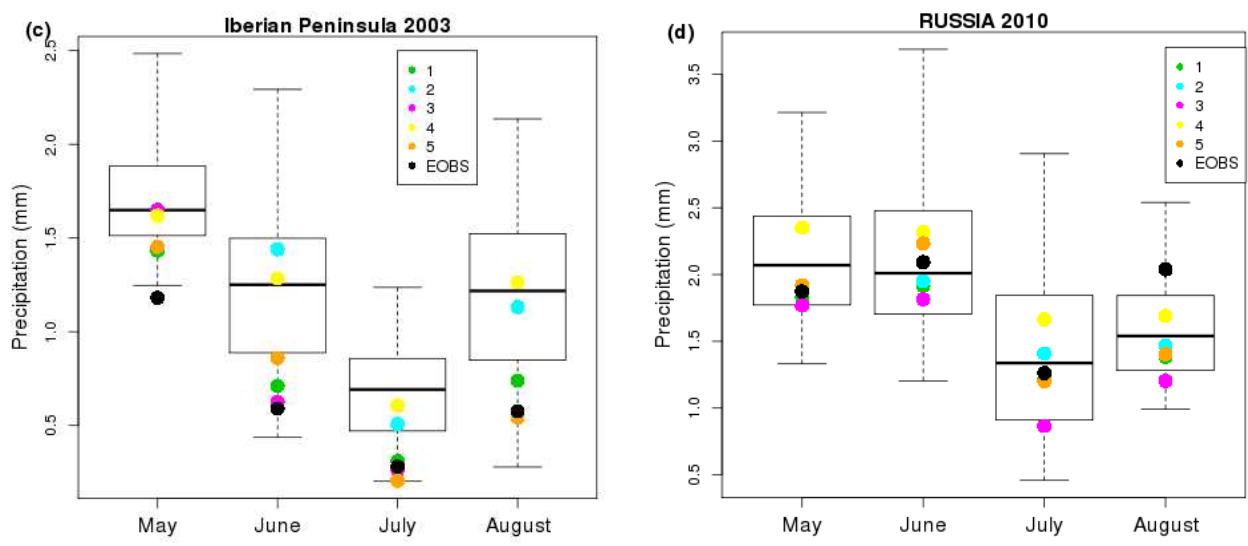

31
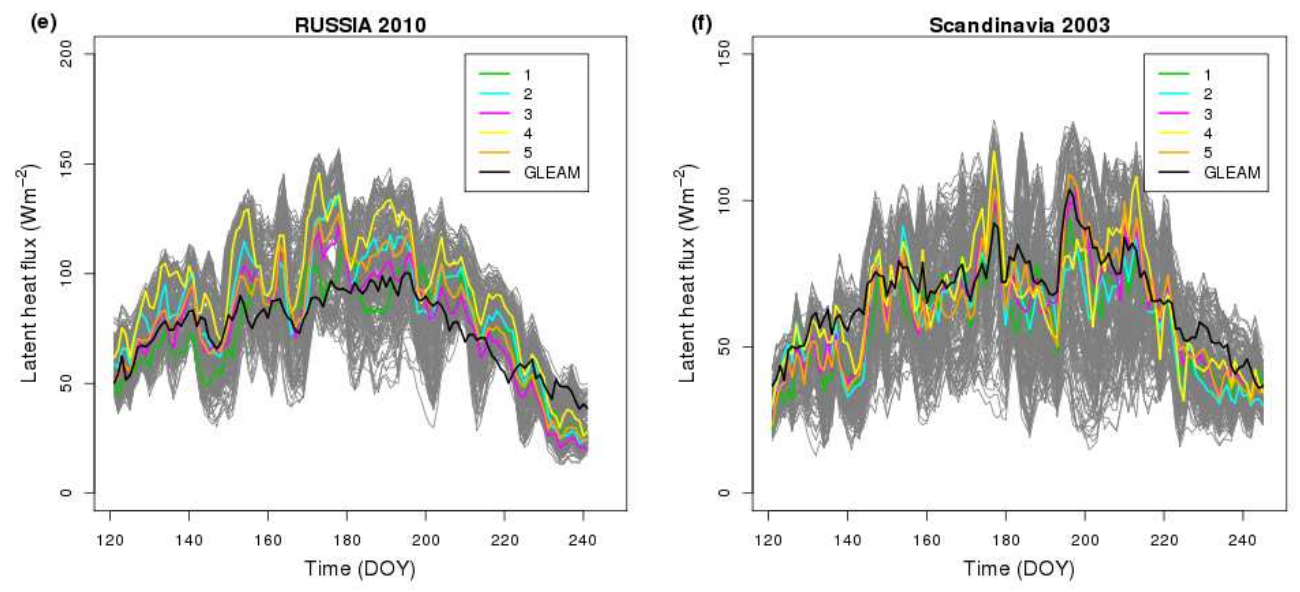